\title{
EU SOU MELHOR DO QUE VOCÊ! GESTÃO PROFISSIONAL X GESTÃO FAMILIAR: A EXPERIÊNCIA DE UMA EMPRESA DE ALIMENTAÇÃO
}

\author{
Henrique Muzzio - Universidade Federal de Pernambuco ${ }^{1}$ \\ Omero Galdino da Silva Júnior - Universidade Federal de Pernambuco ${ }^{2}$
}

Resumo: Esta pesquisa tem como objetivo analisar um processo inicial de profissionalização de uma empresa familiar do ramo de alimentos. O fenômeno das empresas familiares é bastante corriqueiro na realidade brasileira e há um debate em aberto no qual essas organizações podem comportar visões diferentes sobre o gerenciamento da empresa em virtude da contratação de gestores não familiares. De um lado, a profissionalização nas empresas familiares pode acontecer como forma de trazer mais racionalidade a essas organizações. Por outro lado, pode significar uma ruptura com valores culturais. Com uso de metodologia qualitativa, a partir de uma estratégia de estudo de caso, foram realizadas entrevistas com familiares e não familiares. Os resultados evidenciaram um processo em construção, com choques culturais entre novos e velhos valores.

Palavras-chave: Empresa Familiar; Profissionalização; Mudança Organizacional; Valores.

\section{AM BETTER THAN YOU! MANAGEMENT X FAMILY MANAGEMENT: THE EXPERIENCE FROM A FOOD COMPANY}

Abstract: This research aims to analyze an initial process of professionalization of a family business in the food sector. The phenomenon of family businesses is quite commonplace in the Brazilian reality and there is an open debate in which these organizations can hold different views on the management of the company, due to the hiring of non-family managers. On one hand, the professionalization in family firms may happen as a way to bring more rationality to these organizations. On the other hand, it can mean a rupture with cultural values. With use of qualitative methodology, from a strategy of a case study, interviews with familiar and unfamiliar were performed. The results show a process in construction, with culture clashes between new and old values.

Keywords: Family Business; Professionalization; Organizational Change; Values.

\section{Introdução}

Não é de hoje que há um debate sobre as empresas familiares quanto ao seu processo de gestão. Esse debate está ancorado em uma perspectiva de racionalidade e capacidade de gestão. Em outras palavras, busca-se compreender qual a melhor opção estratégica para esse tipo de negócio permanecer sob a tutela

\footnotetext{
${ }^{1}$ E.mail: henrique.muzzio@ufpe.br - Endereço: Av. Prof. Moraes Rego, 1235 - Cidade Universitária, Recife - PE - CEP: 50670-901.

2 E.mail: omerogaldino@gmail.com
}

DOI: 10.14211/regepe32120. MUZZIO, H.; SILVA JÚNIOR, O. G.. Eu sou melhor do que você! Gestão profissional x gestão familiar: a experiência de uma empresa de alimentação. Revista de Empreendedorismo e Gestão de Pequenas Empresas, v. 3, n. 2, p. 3-19, 2014. 
de membros da família fundadora ou aderir a uma gestão realizada por profissionais não familiares.

O conceito de empresa familiar para a análise aqui proposta é uma organização gerida com a intenção de formar e prosseguir a visão dos negócios detidos por uma coalizão dominante, controlada pelos membros de uma ou de poucas famílias, de maneira que seja potencialmente sustentável entre gerações (CHITTOOR; DAS, 2007, HALL; NORDQVIST, 2008).

O fenômeno de empresas familiares é difundido mundialmente, normalmente representando uma expressiva parcela da economia. No mercado brasileiro isso não é diferente, ou seja, há um grande espaço da atividade econômica brasileira que é desenvolvido por empresas familiares, muitas delas, de menor porte econômico. É bem verdade que essas empresas não possuem tanto espaço na mídia de negócios, talvez dando a impressão de que o mercado é dominado apenas por grandes corporações (BORGES; LESCURA; OLIVEIRA, 2012).

No mercado de alimentos, esse fenômeno se repete. Há um grande espaço midiático para redes mundiais de fast-food, por exemplo, que se instalaram no Brasil, atraindo grande interesse do mercado consumidor e da imprensa. Porém, o mercado ainda é significativamente atendido por empresas de menor porte, incluindo as familiares que, nesse caso, se viram diante de uma forte concorrência oriunda de redes alimentícias multinacionais. Com isso, esse tipo de organização menos tradicional procura realizar planejamentos estratégicos a fim de sobreviver no mercado, o que contribui para que parte dessas empresas se veja como competitivas em seu mercado de atuação (PCR, 2014).

Não exclusivamente para esse setor econômico, o debate na academia e no mercado é o da pertinência (ou não) de profissionalizar as empresas familiares que já alcançaram um porte econômico relativo e que, portanto, necessitariam ser geridas por profissionais não familiares em função de uma capacidade de gestão superior na qual é afastado o risco das decisões "sentimentais" envolvidas nas relações familiares.

Nesse sentido, acredita-se que tais empresas só podem atingir um nível ótimo ao se profissionalizarem e parte do poder, que encontra-se nas mãos de membros da 
família proprietária do negócio, seja partilhado com gestores não familiares, pois só assim estariam livres da influência das variáveis emocionais e o processo decisório seria o mais racional possível. Entretanto, a literatura sobre o tema não é conclusiva, embora a profissionalização da gestão tenha se tornado comum em virtude da busca por uma (suposta) maior eficiência gerencial. Existe uma expressiva profusão da literatura sucessória, mas pouca atenção tem sido dada ao relacionamento entre profissionalização da gestão e a performance da sucessão (LE BRETON-MILLER; MILLER; STEIER, 2004; LE BRETON-MILLER; MILLER, 2006).

Para contribuir com o debate aberto, o presente estudo visa entender como se dá a relação entre a gestão familiar e as relações familiares inseridas no contexto de um negócio familiar do ramo alimentício, analisando suas particularidades e características. Para tanto, o objetivo deste artigo é identificar as nuances da gestão de uma empresa familiar que passa por um processo de profissionalização, desencadeando novas significações nas relações familiares, na estrutura, na gestão da organização e na visão simbólica da figura do fundador.

Este artigo foi dividido em mais seis partes. A primeira fala sobre a profissionalização nas empresas familiares. A segunda divisão discute a imagem e o legado que um fundador pode imprimir em uma organização. Logo após, são explicitados os procedimentos metodológicos da pesquisa de campo, com o objetivo de inferir maior legitimidade nesse problema de pesquisa. A próxima seção traz informações sobre a empresa objeto do estudo. Posteriormente, são feitos comentários acerca dos resultados da pesquisa e, em seguida, são tecidas as considerações finais.

\section{Cultura e a gestão familiar}

Essa pesquisa analisa a cultura organizacional a partir da sua compreensão como sendo uma rede de significações que circulam dentro e fora do espaço organizacional e continuamente criada nas relações cotidianas. Essas relações são simultaneamente ambíguas e contraditórias, podendo revelar tanto a coesão como a fragmentação organizacional (MARTIN, 1992).

DOI: 10.14211/regepe32120. MUZZIO, H.; SILVA JÚNIOR, O. G.. Eu sou melhor do que você! Gestão profissional x gestão familiar: a experiência de uma empresa de alimentação. Revista de Empreendedorismo e Gestão de Pequenas Empresas, v. 3, n. 2, p. 3-19, 2014. 
Nas organizações familiares, a cultura e todo o seu escopo estão vinculados principalmente à figura de seu fundador. Esta associação é normalmente construída em razão de um histórico marcado por condições iniciais críticas em que se exige grandes esforços dos atores iniciais, o que acaba por ser simbolicamente (re)significado por uma atitude até mesmo heróica desse fundador, que foi o líder responsável por consolidar o desenvolvimento organizacional (MUZZIO, 2012).

O empreendedor, como indivíduo que possui experiências, pontos de vistas, preferências e características ímpares, forma e cria a cultura inicial. Em seguida, as interações com os indivíduos criam um processo de formação e influência simultânea, fato marcante da cultura organizacional e que também está presente nas empresas familiares (SCHEIN, 2004).

A cultura é como uma "cola social" (PRESTES MOTTA, 1997). Com ela, as empresas se integram e são regidas pelas relações informais, pelos valores e crenças compartilhados. Esse conjunto forma a história de uma organização (ALVESSON, 1993). Os valores organizacionais podem ser entendidos em diferentes níveis, em contextos presentes ou futuros e, ainda assim, são assumidos para orientar os membros em sua seleção ou avaliação do comportamento (BOURNE; JENKINS, 2013).

Dessa forma, a cultura organizacional indica 0 que os indivíduos pertencentes a uma determinada empresa terão como norte em suas ações. Nas organizações familiares, esse conceito se torna ainda mais forte e presente, sobretudo pela intensa associação do líder e sua trajetória de vida, e pelo reforço que a presença da família no negócio impacta nessa rede de valores.

Um dos componentes culturais importantes no contexto familiar é o legado do fundador. Para além da perspectiva que o negócio está intimamente ligado à noção de propriedade, o que faz com que o direito de controle da organização recaia sobre esse criador, o fundador forma um legado que inspira gerações a transferirem valores e crenças no futuro para outras gerações, tornando-se uma referência simbólica. Seu histórico de lutas e conquistas que marca inicialmente a empresa gera nos funcionários, por vezes, um sentimento de admiração.

DOI: 10.14211/regepe32120. MUZZIO, H.; SILVA JÚNIOR, O. G.. Eu sou melhor do que você! Gestão profissional x gestão familiar: a experiência de uma empresa de alimentação. Revista de Empreendedorismo e Gestão de Pequenas Empresas, v. 3, n. 2, p. 3-19, 2014. 
O fato de existir na própria empresa um exemplo de superação na figura de um fundador, torna-o um modelo a ser seguido. Assim, há um simbolismo inerente à imagem do criador, associada a valores bastante respeitados e à história acerca do nascimento da empresa, das dificuldades enfrentadas no início e como a empresa cresceu no decorrer dos anos. Os fundadores promovem um processo de aprendizagem coletiva na medida em que os componentes culturais são repassados e perpetuados para outros membros que veem depois. A sua imagem na organização é associada à figura de um herói que superou dificuldades na realização do sonho, cujos princípios e valores serão significativos ao longo do tempo, assumindo um papel mítico (MENDONÇA, 2006).

Em caso de transferência de poder para uma segunda geração familiar, o que se espera é que a cultura e os valores referenciados no legado do fundador ainda estejam fortemente presentes no contexto organizacional. Nesse caso, ainda que os filhos possam imprimir um novo rumo aos negócios, ainda será uma empresa familiar, dotada de muitos dos elementos simbólicos que subsidiam as práticas organizacionais. De forma mais significativa, uma mudança relevante tanto estrutural como simbólica seria mais esperada em processos de profissionalização da gestão.

\section{A profissionalização nas empresas familiares}

Esse estudo parte do princípio de que a profissionalização é um conjunto de ações que culmina na passagem, de todo ou parte, do poder decisório para executivos não familiares, com o objetivo de tornar a gestão mais efetiva nas áreas funcionais da administração em busca de melhor eficiência organizacional e a sobrevivência da empresa (LE BRETON-MILLER; MILLER; STEIER, 2004, LE BRETON-MILLER; MILLER, 2006; CHITTOOR; DAS, 2007; HALL; NORDQVIST, 2008, MUZZIO, 2013).

A profissionalização nas empresas familiares pode acontecer como forma de proporcionar um comportamento legitimado no mercado em que há uma vinculação com tal prática e maior racionalidade às práticas organizacionais (MUZZIO, 2013). A literatura voltada para as pequenas empresas familiares evidencia uma pressão 
institucional para que essas organizações desencadeiem a profissionalização da gestão, o que seria um processo natural ou quase obrigatório (ZHANG; MA, 2009).

No início, toda a empresa é moldada pelos desejos de seu fundador, que possui pontos de vista e opiniões acerca do negócio, os quais servem para que a organização seja formada, bem como para consolidar sua cultura (SCHEIN, 2004).

A gestão profissional é vista como a alternativa racional ao nepotismo e aos conflitos familiares que normalmente atormentam esses negócios. Dyer (1989) apresenta três caminhos pelos quais a profissionalização na empresa familiar pode ocorrer, a saber: profissionalizar membros da família proprietária do negócio; profissionalizar os empregados que já trabalham na firma; e trazer gestores profissionais de fora da organização.

Em referência ao primeiro caminho, uma das questões que dificulta a profissionalização de familiares proprietários está no seguinte problema: enraizou-se na literatura que a vinda de administradores profissionais para as empresas familiares é crucial se o objetivo é trazer maior racionalidade a essa organização que, normalmente, também se pauta sobre aspectos afetivos comuns ao ambiente familiar. Entretanto, essa condição não pode ser dada como certa.

Conforme lecionam Hall e Nordqvist (2008), há uma noção simplista de gestão profissional dominante na literatura, associando a gestão de membros da família como não profissional. Ainda segundo esses autores, a noção de membros familiares como gestores não profissionais que precisam ser substituídos por profissionais para o bem da empresa levou ao pressuposto de que a sobrevivência das empresas familiares dependia de administradores que não possuíam laços afetivos com elas.

A forma mais usual para a profissionalização seria o terceiro caminho apontado por Dyer (1989). Se isso pode significar ganhos na gestão, há lacunas a serem consideradas. Ao trazer profissionais para a gestão da organização, há uma tendência de que surjam conflitos. Dessa forma, num processo de profissionalização, haverá um choque entre o fundador, inspirador inicial da cultura organizacional, e os gestores profissionais não familiares, em virtude do descompasso entre os valores que esses agentes possuem. É normal que a 
expertise da cultura organizacional do criador seja bem mais expressiva que a dos administradores não familiares. Estes, por sua vez, podem possuir um conhecimento técnico-gerencial superior.

Com a transferência do controle administrativo para gestores profissionais, é comum que novos padrões de liderança sejam formados, reorientando a cultura organizacional através de novas estratégias voltadas ao crescimento e à expansão do negócio. Esses gestores, na maioria das vezes, possuem alto nível de educação voltada para os negócios, como pós-graduações e especializações. Este fator os diferencia dos familiares que estão na gestão da empresa, pois se supõe haver menor capacidade e/ou maior apelo emocional nas decisões tomadas pelos familiares.

Outra questão a considerar é que, normalmente, pode ocorrer um gap entre a entrada de profissionais trazidos de fora da organização para a gestão do negócio e a transferência de certo poder para esses colaboradores. A profissionalização não é apenas um ato onde há uma formalização de nova liderança não pertencente à família fundadora. Mais do que isto, trata-se de um processo que demanda tempo de maturação das reais transformações implantadas pelas novas lideranças (STEWART; HITT, 2012; MUZZIO, 2013).

Como gera uma mudança organizacional, é normal que a profissionalização provoque situações diversas, como: conflitos, negação ao novo modelo de gestão, entusiasmo com a inovação, envolvimento com os novos valores propostos, demissões de funcionários que se encontram resistentes e não mais se enquadram com o perfil futuro da empresa. Isso pode ocorrer em virtude da dissonância dos valores praticados pelo fundador e os propostos pelos novos administradores. Dessa forma, não é possível estabelecer a duração exata do período de ajustamento, pois depende do grau em que os pilares da organização estiverem institucionalizados.

Mesmo em face de toda a complexidade que esse processo pode gerar na organização, a literatura sobre o tema se mantém favorável no que diz respeito à vinda de profissionais não familiares para fazerem parte do corpo diretivo, sobretudo em resposta à acirrada competitividade do ambiente externo e em busca do crescimento da empresa no setor em que atua. 
Porém, há um debate em aberto e os relatos de experiências acabam por contribuir para uma maior envergadura do campo das empresas familiares, profissionalizadas ou não. É nesse sentido que são apresentadas as seções seguintes.

\section{Metodologia}

Essa pesquisa foi realizada em um grupo de empresas familiares chamadas de Grupo X neste estudo. Esse grupo de empresas atua na área de alimentação fora do lar e possui mais de 30 anos de experiência no setor.

Essa pesquisa possui uma orientação qualitativa, pois usa como principal recurso a subjetividade, as interpretações e as condições únicas do campo de pesquisa. Pesquisas de natureza qualitativa envolvem grande variedade de materiais empíricos, que podem ser estudos de caso, experiências pessoais, histórias de vida, relatos de introspecções, produções, artefatos culturais, interações, enfim, materiais que descrevam a rotina e os significados da vida humana em grupos (CESAR, 2005).

Nessa análise, foi utilizado como estratégia de pesquisa, o estudo de caso. Essa escolha se deu devido ao foco da pergunta de pesquisa estar em questões do tipo "como" e "por que", levando em consideração os aspectos práticos que são corroborados pelas teorias propostas no referencial teórico.

Foi utilizada uma entrevista semiestruturada como instrumento de pesquisa, podendo ser definida como "técnica alternativa para se coletar dados não documentados sobre um determinado tema" (PÁDUA, 2000, p. 66). As entrevistas têm largo uso em estudos dessa natureza e são úteis no mapeamento e compreensão do mundo da vida dos respondentes, servindo para que o cientista social faça uso da interpretação para compreender as opiniões dos atores em termos mais conceituais e abstratos (GASKELL, 2002). 
O tipo da entrevista foi escolhido por apresentar um roteiro previamente confeccionado e permitir que o entrevistado responda as perguntas segundo sua percepção.

Dessa forma, foram coletadas informações a partir de 8 (oito) entrevistas realizadas com funcionários familiares e não familiares do Grupo X. As entrevistas ocorreram nas dependências do grupo investigado e tiveram em média 30 minutos de duração. Os participantes ficaram cientes da natureza e dos propósitos da pesquisa e foi garantido o anonimato de cada um.

Os dados foram tratados por análise de discurso, já que o estudo "demanda a utilização de uma estratégia de pesquisa metodologicamente sofisticada, capaz tanto de interpretar as mensagens explícitas quanto de desvendar os sentidos ocultos, os silêncios, as omissões" (CABRAL, 2005).

\section{O grupo pesquisado}

Este estudo de caso é baseado no Grupo X (identidade preservada). As informações foram colhidas através de matérias em jornais, revistas e testemunhos de pessoas relacionadas ao negócio. O grupo possui mais de 32 anos de atuação em Recife, capital do Estado de Pernambuco, contando com 9 marcas diferentes e quase 250 funcionários para atender a essas operações.

O grupo é comandado por 2 (dois) irmãos, os mais velhos de uma família de 9 (nove) filhos, que chegaram ao Recife em 1977 ainda adolescentes para buscarem melhores condições de vida. Atualmente, possuem uma rede de restaurantes bem sucedida, sendo exemplos de luta e determinação, o que ajuda a compor o quadro cultural de caminho árduo, mas vitorioso, como ressaltado na literatura (FREITAS, 1991). As operações são divididas entre 9 (nove) estabelecimentos e vão desde culinária regional à japonesa.

O empreendimento ainda não é totalmente profissionalizado, visto que, conforme já evidenciado, a profissionalização só é efetivada quando parte ou todo o processo decisório é repassado às novas lideranças. Contudo, o chefe de escritório da empresa, filho de um dos fundadores, tenta atrair profissionais para mudar esse 
quadro, processo que se iniciou no começo de 2013. Vale ressaltar que o empreendimento ainda está na sua primeira geração, pois os fundadores ainda continuam ativos na gestão do negócio e seus filhos os ajudam nessa tarefa.

Segundo a visão determinada pelo grupo, o objetivo principal é tornar-se líder no mercado recifense e ser a mais admirada do setor gastronômico por sua combinação de lucratividade e autêntica vocação em servir seus clientes. Os principais valores são: comprometimento em garantir a melhor experiência gastronômica e qualidade, através do alto padrão estabelecido sobre os produtos e serviços oferecidos.

A estratégia do grupo, portanto, que antes era baseada nos custos, agora é de diferenciação. Pode-se observar isso na evolução do negócio. O público do primeiro restaurante aberto na época era formado por turistas e jovens em fim de noite, atraídos pelo horário amplo de fechamento e pelas porções generosas dos pratos combinados com um ambiente simples.

Paradoxalmente, a última casa a ser lançada na praça de Boa Viagem (Bairro) tem um apelo para a culinária regional e um atrativo para turistas do Brasil e do mundo, funcionando tanto como self-service como $A$ La Carte. Além disso, possui um deck, bastante convidativo para aproveitar momentos de descontração com família e amigos, e um balcão na parte externa que simula uma lanchonete do interior. Essa operação logo se destacou pela sua diferença arquitetônica e um ambiente distinto dos demais, atraindo clientes de melhores condições financeiras. Atualmente, essa casa é uma das principais responsáveis pelos resultados financeiros do grupo.

\section{A visão da profissionalização}

Mesmo que o processo de profissionalização ainda não tenha atingido o seu grau de maturidade, pode-se dizer que há uma boa desenvoltura da gestão profissional no Grupo X. As dificuldades de atuação desses funcionários na organização são evidentes e ocorrem no dia a dia de suas atribuições, em virtude de uma gestão predominantemente autocrática e centralizadora.

DOI: 10.14211/regepe32120. MUZZIO, H.; SILVA JÚNIOR, O. G.. Eu sou melhor do que você! Gestão profissional x gestão familiar: a experiência de uma empresa de alimentação. Revista de Empreendedorismo e Gestão de Pequenas Empresas, v. 3, n. 2, p. 3-19, 2014. 
Além dessa barreira inerente do processo de profissionalização em negócios familiares, o fato de ser pioneiro nesse tipo de estratégia no setor em que atua, torna ainda mais difícil de mensurar a efetividade desse tipo de ação por parte dos diretores do grupo, por exemplo. Alia-se a isso as particularidades inerentes ao simbolismo, no qual as informações são, por vezes, elaboradas a partir de uma codificação e carregada de subjetividade, o que torna mais difícil o processo para gestores que estão em um processo que ainda não se consolidou a profissionalização na empresa familiar (MUZZIO, 2013).

Segundo a visão dos entrevistados, a empresa familiar é bem gerida pela família, pois possui expertise do negócio. No entanto, a gestão teria pouca experiência em outras áreas e ainda uma dificuldade de separar o pessoal do profissional. $\mathrm{Na}$ visão dos respondentes, os aspectos familiares influenciam na administração, visto que há uma autoridade a ser seguida e laços afetivos marcando essas relações (HALL; NORDQVIST, 2008).

No entanto, pode-se cometer um engano ao achar que uma organização familiar possui apenas desvantagens. De acordo com os entrevistados, a confiança e a certeza de que numa dificuldade "aquela pessoa vai estar ali" são aspectos que não podem ser negligenciados. Não é difícil reconhecer nessa afirmativa uma forte conotação simbólica em que se evidencia a presença marcante dos laços afetivos comuns nas empresas familiares. Mesmo assim, a gestão acreditou ser indispensável a vinda de pessoas não relacionadas à família para trazer mais racionalidade ao negócio (LE BRETON-MILLER; MILLER; STEIER, 2004).

Nesse sentido, o Funcionário Familiar B diz: "Tem um limite, que quando chega um momento ela tem que se profissionalizar. $O$ fator familiar ele tem um limite. Chega um momento que só com a família você não consegue gerir um negócio. As gerações seguintes não conseguem acompanhar a ideologia, a cultura das gerações anteriores".

Essa visão foi corroborada pela resposta de outros entrevistados que, quando questionados se a vinda de profissionais não familiares para a gestão das empresas teria trazido algum diferencial para o negócio, responderam positivamente e apresentaram as melhorias dessa ação: "Quem vem de fora, vem com novos 
conhecimentos, visões e talvez veja defeitos e qualidades da rotina, do que não vemos na correria do dia a dia. Isso é muito comum. As pessoas podem enxergar aquilo que você não identifica ou acha que está normal. Foi um processo bastante enriquecedor" (Funcionária Familiar $\mathrm{C}$ ).

Esses depoimentos evidenciam a necessidade da presença de gestores profissionais nas empresas familiares, não necessariamente como os únicos protagonistas. Os familiares reconhecem seus limites e a característica positiva dos gestores profissionais ao trazer "novas visões de mundo" ao negócio.

Quando perguntados sobre os processos da organização, a maioria confirmou a existência de informalidade, bem como os processos organizacionais baseados em uma forte relação informal a partir da posição familiar do "dono" e o choque que isso desencadeia com os gestores não familiares: "Sou do RH e muitos funcionários só chegam pra me comunicar das suas férias. Antes que questione alguma coisa, eles já dizem: 'Falei com o dono'. Não fico chateado, pois esse mecanismo já ocorria antes de minha chegada ao restaurante." (Funcionário Não Familiar W).

Essa informalidade de processos fica ainda mais clara no caso do trato com funcionários familiares. É importante observar que a condição de pertencer à família fundadora do negócio dá certa vantagem ao colaborador: "Por exemplo, eu sempre bato muito forte na tecla da alimentação. Quando o cara é familiar, ele é diferenciado [...] O cara pode pedir uma picanha, um filé mignon, uma pescada amarela, tudo que ele quiser. Já o não familiar, não. Se trabalhamos numa empresa que preza pela isonomia, não há porque existir essa diferença. Isso é um dos pontos mais importantes, do meu ponto de vista, que eu acho que isso acaba desmotivando quem não é da família a não estar no negócio." (Funcionário Familiar B).

Esses e outros exemplos evidenciam as dificuldades enfrentadas pelos gestores profissionais não familiares em que há uma série de obstáculos para o desempenho no negócio familiar. Dentre os mais citados por esses pesquisados está a falta de confiança de alguns familiares, principalmente dos donos do negócio. Por outro lado, os familiares esperam que esses gestores possam "demonstrar a capacidade de gerar melhor oportunidade para os negócios, maximizar lucros e 
minimizar custos. Resumindo: evoluir a empresa em âmbitos que a gente não tem essa visão (familiares)" (Funcionário Familiar A).

Os depoimentos revelam o quão complexo é uma relação entre a gestão familiar e a presença de gestores profissionais que tendem a assumir a liderança do negócio. Dotada de simbolismo e de um forte apelo emocional, a gestão da empresa investigada parece espelhar as contradições e dificuldades que acompanha boa parte das empresas familiares que ao crescer, buscam profissionais no mercado a fim de conseguir maior racionalidade (DYER, 1989). Contudo, essa racionalidade não ocorre de forma profunda, dado a presença do fator família nas práticas e na cultura organizacional.

\section{Imagem e valores dos fundadores}

Por sua tradição e reconhecimento, o Grupo X conta com um corpo funcional que vai desde estagiários até profissionais que estão presentes desde o primeiro restaurante inaugurado. Mesmo assim, com tanta variedade de colaboradores novos e antigos, emergiu nos depoimentos que a maioria vê os fundadores como vitoriosos e os admiram pela força de vontade, comprometimento, perseverança e pelo histórico de luta disseminado através dos simbolismos presentes na organização (FREITAS, 1991; SCHEIN, 2004).

Os valores que os líderes inicialmente difundiram na empresa foram relacionados à humildade e à atitude, trazendo para os colaboradores o senso de que eles também eram responsáveis pela empresa e precisavam ter proatividade diante de certas situações. Dado o início do processo de profissionalização, o choque cultural era esperado e é visto como parte da reestruturação da organização.

Nessa linha, o Funcionário Familiar A diz: "Alguns funcionários entendem a história, por fazer parte dela, e funcionários novos que têm outra mentalidade. Isso gera, algumas vezes, choques na operação".

O funcionário Familiar B evidencia: "A gente já teve muitos familiares no negócio e hoje nós temos menos, porque as pessoas não estavam de acordo com 
os processos, que iam se profissionalizando. Chegou até o ponto em que ficou claro que elas iam de encontro ao que a administração pretendia, não aceitando novos procedimentos de controle, por exemplo, e pediram para sair da empresa [...] Se a gente tinha processos financeiros que teriam que ser incorporados, eles não aceitavam, relutavam, e chegou um momento em que eles se sentiram excluídos, pois não contribuíam mais para o negócio.”.

Esses depoimentos mostram os choques culturais que surgem no processo de profissionalização. Com a incorporação de novos valores, frente os arraigados na cultura organizacional, alguns participantes não se veem vinculados aos novos elementos simbólicos estabelecidos e acabam saindo do contexto organizacional por não se identificarem com um novo simbolismo estabelecido (MUZZIO, 2012).

Atualmente, é consenso que algumas coisas mudaram, embora o poder continue bastante centralizado na figura dos dois empreendedores, até porque o processo de profissionalização ainda não foi finalizado. O Funcionário Não Familiar W afirmou que estava notando um avanço à medida que as pessoas do escritório traziam novas ideias. Várias foram as melhorias citadas pelos respondentes, como: melhor diálogo entre familiares e os funcionários não familiares, maior flexibilidade e profissionalismo.

Em última análise, pode-se observar que não é um processo simples para os familiares, funcionários e os novos gestores profissionais. É um novo contexto com novos valores que se chocam com as práticas enraizadas. É um contexto externo extremamente dinâmico e competitivo. Enfim, é um processo em desenvolvimento ainda a se solidificar simbolicamente.

\section{Considerações finais}

A tendência à profissionalização, que faz parte da literatura dominante sobre a administração de pequenas empresas, sobretudo as familiares, tem ganhado volume e respaldo entre os profissionais da área. Ao trazer uma experiência concreta, esta pesquisa procurou subsidiar ainda mais o debate estabelecido, 
demonstrando perspectivas, principalmente em virtude de tantas variáveis, inclusive as emocionais (LE BRETON-MILLER; MILLER; STEIER, 2004).

O presente artigo entende que o conceito de profissionalização precisa ir além do indicado pelas tradicionais pesquisas na área que o define apenas pela posse de qualificações formais, treinamento e educação. Também é necessária a compreensão da cultura, tanto dos familiares quanto do negócio por eles criado (HALL; NORDQVIST, 2008).

Na empresa estudada, a profissionalização iniciou-se há pouco tempo, mas já apresenta sinais de certa desenvoltura. A vinda de profissionais para a gestão do negócio proporcionou a mudança de certos hábitos, como a comunicação entre os familiares. Como dito por um funcionário da empresa, "chega ser até interessante ver pai e filho se tratando como chefe e funcionário".

O choque entre a cultura difundida pelos fundadores e a visão dos profissionais não familiares orientados à racionalização do negócio, se encontra amenizado em virtude da concentração do poder na figura dos líderes. No entanto, através da pesquisa com os funcionários não familiares, é notória a importância que esses colaboradores dão às mudanças na estrutura e em certas práticas administrativas que, segundo eles, precisam se adaptar ao contexto do setor em que a empresa atua.

Contudo, os aspectos familiares e os laços emotivos inerentes à condição humana, influem algumas vezes no processo decisório e nos demais aspectos relacionados ao gerenciamento dos restaurantes. Como citado anteriormente, também se percebe que há privilégio no tratamento com os funcionários familiares. Uma questão que emerge é se seria necessária uma completa ausência desses traços afetivos para que um negócio familiar seja bem sucedido. Se for, isso não iria de encontro à natureza desse tipo de negócio?

Por fim, torna-se essencial destacar a importância que o tema tem para a gestão dos negócios familiares. Diante da pouca literatura nacional, há um campo em aberto para ser explorado. Nesse sentido, outras pesquisas que evidenciem experiências de profissionalização em empresas familiares irão suprir essa lacuna. Esse fato será significativo e valioso para acadêmicos interessados em entender o

DOI: 10.14211/regepe32120. MUZZIO, H.; SILVA JÚNIOR, O. G.. Eu sou melhor do que você! Gestão profissional x gestão familiar: a experiência de uma empresa de alimentação.

Revista de Empreendedorismo e Gestão de Pequenas Empresas, v. 3, n. 2, p. 3-19, 2014. 
fenômeno e preocupados em melhorar as dificuldades operacionais e simbólicas desse processo.

\section{Referências}

ALVESSON, M. Cultural Perspectives on Organisations. 1 ed. Cambridge: Cambridge University Press, 1993. 140 p.

BORGES, A. F.; LESCURA, C.; OLIVEIRA, J. L. O campo de pesquisas sobre empresas familiares no Brasil: análise da produção científica no período 1997-2009. Organizações \& Sociedade, v. 19, n. 61, p.315-332, 2012.

BOURNE, H.; JENKINS, M. Organizational Values: A Dynamic Perspective. Organization Studies, v. 34, n. 04, p. 495-514, 2013.

CABRAL, A. C. de A. A análise do discurso como estratégia de pesquisa no campo da Administração: uma visão global. Contex - Revista contemporânea de Economia e Gestão, v. 3, n. 1, p. 59-68, 2005.

CESAR, A. M. R. V. C. Método do Estudo de Caso (Case Studies) ou Método do Caso (Teaching Cases)? Uma análise dos dois métodos no ensino e pesquisa em Administração. REMAC: Revista Eletrônica Mackenzie de Casos. São Paulo, 2005. Disponível em: <http://www.mackenzie.br/fileadmin/Graduacao/CCSA/remac/jul_dez_05/06.pdf>. Acesso em 16 jan. 2014.

CHITTOOR, R., DAS, R. Professionalization of management and succession performance - a vital linkage. Family Business Review, v. 20, n. 1, p. 65-79, 2007.

DYER, W. G. Jr. Integrating professional management into a family owned business. Family Business Review, v. 2, n. 3, p. 221-235, 1989.

FREITAS, M. E. Cultura Organizacional: formação, tipologias e impactos. São Paulo: Makron Books, McGraw-Hill, 1991.

GASKELL, G. Entrevistas individuais e grupais. In: BAUER, M. W.; GASKELL, G. (Orgs.), Pesquisa qualitativa com texto, imagem e som: um manual prático. Petrópolis: Vozes, 2002, p. 64-89.

HALL, A.; NORDQVIST, M. Professional management in family businesses: toward an extended understanding. Family Business Review, v. 21, n. 1, p. 51-68, 2008.

LE BRETON-MILLER, I.; MILLER, D. Why Do Some Family Businesses OutCompete? Governance, Long-Term Orientations, and Sustainable Capability. Entrepreneurship Theory and Practice, v. 30, n. 6, p. 731-746, nov. 2006.

DOI: 10.14211/regepe32120. MUZZIO, H.; SILVA JÚNIOR, O. G.. Eu sou melhor do que você! Gestão profissional x gestão familiar: a experiência de uma empresa de alimentação. Revista de Empreendedorismo e Gestão de Pequenas Empresas, v. 3, n. 2, p. 3-19, 2014. 
LE BRETON-MILLER, I.; MILLER, D.; STEIER, L. P. Towards an integrative model of effective FOB succession. Entrepreneurship Theory \& Practice, v. 28, n. 4, p. 305328, 2004.

MARTIN, J. Culture in Organizations: three perspectives. New York: Oxford University Press, 1992, 209 p.

MENDONÇA, S. L. F. Os sentidos da morte do fundador de uma empresa familiar: uma abordagem sócio-construcionista. 2006. 118f. Dissertação (Mestrado em Administração) - Universidade Federal de Lavras, Lavras, 2006.

MUZZIO, H. Racionalidades em jogo em um processo de profissionalização organizacional. Revista de Administração Contemporânea, v. 16, n. 6, p. 827-844, 2012.

A Consolidação da Profissionalização da Empresa Familiar e o Legado do Fundador: concepções teóricas e implicações práticas. Teoria e Prática em Administração, v. 3 n. 2, p. 27-43, 2013.

PÁDUA, E. M. M. de. Metodologia da Pesquisa: abordagem teórico-prática. Campinas: Papirus, 2000, 132 p.

PCR - Price Waterhous e Coopers Auditores Independentes. Empresas familiares no Brasil. Cenário e desafios. Disponível em: <http://www.pwc.com.br/pt/publicacoes/assets/empresa-familiar-brasil-11A.pdf>. Acesso em jan. 2014.

PRESTES MOTTA, F. C. Cultura e Organizações no Brasil. In: PRESTES MOTTA, F. C.; CALDAS, M. P. (Org.) Cultura Organizacional e Cultura Brasileira. São Paulo: Atlas, 1997. p. 25-37.

SCHEIN, E. H. Organizational culture and leadership. 3. ed. San Francisco: Jossey-Bass, 2004, 279 p.

STEWART, A.; HITT, M. Why Can't a Family Business Be More Like a Nonfamily Business? Modes of Professionalization in Family Firms. Family Business Review, v. 25, n. $1,2012$.

ZHANG, J., MA, H. Adoption of professional management in Chinese family business: A multilevel analysis of impetuses and impediments. Asia Pacific Journal Management, v. 26, n. 1, p. 119-139, 2009.

Artigo recebido em: 27/02/2014. Artigo aprovado em: 14/08/2014

DOI: 10.14211/regepe32120. MUZZIO, H.; SILVA JúNIOR, O. G.. Eu sou melhor do que você! Gestão profissional x gestão familiar: a experiência de uma empresa de alimentação. Revista de Empreendedorismo e Gestão de Pequenas Empresas, v. 3, n. 2, p. 3-19, 2014. 